\title{
Potential Therapeutic Strategies for Severe Anaphylaxis Targeting Platelet-Activating Factor and PAF Acetylhydrolase
}

Julia Upton, $M D^{1,2, *}$

Peter Vadas, MD, PhD ${ }^{3,4}$

\author{
Address \\ ${ }^{*}, 1$ Clinical Immunology and Allergy, Department of Pediatrics, The Hospital for \\ Sick Children, Room 7280555 University Ave., Toronto, ON M5G 1X8, Canada \\ Email: Julia.upton@sickkids.ca \\ ${ }^{2}$ University of Toronto, Toronto, 0N, Canada \\ ${ }^{3}$ Division of Allergy and Clinical Immunology, St. Michael's Hospital, Carter \\ Wing 8-161 30 Bond St., Toronto, ON M5B 1W8, Canada \\ ${ }^{4}$ Department of Medicine, University of Toronto, Toronto, 0N, Canada
}

Published online: 15 May 2014

(C) Springer International Publishing AG 2014

Keywords Platelet-activating factor - Platelet-activating factor acetylhydrolase - Platelet-activating factor receptor antagonists . Anaphylaxis - Methylene blue - Ginkgolide

\section{Opinion statement}

Characterization of mediators and mechanisms of anaphylaxis will allow for more specific and effective treatment with fewer side effects. Recent studies have shown that platelet-activating factor (PAF) is a pivotal mediator of the life-threatening manifestations of anaphylaxis. The putative role of PAF in human anaphylaxis is based on a large body of evidence in experimental and human anaphylaxis. In animal models of anaphylaxis, intravenous administration of PAF reproduces the severe physiologic derangements of anaphylaxis. PAF receptor knock-out mice are resistant to experimental anaphylaxis. Data from human anaphylaxis show that levels of PAF increase proportionately with the severity of anaphylaxis, whereas a deficiency in the enzyme that inactivates PAF predisposes to severe or fatal anaphylaxis. Many of the biologic effects of PAF appear to be transduced by nitric oxide production. PAF receptor antagonists protect against the lethal effects of exogenous PAF, but, importantly, also protect against experimental anaphylaxis following allergen challenge. Mice treated with an enzyme that inactivates PAF are similarly resistant to anaphylaxis. Some clinically available medications for anaphylaxis act at different points of the PAF pathway. Epinephrine, the first-line treatment for anaphylaxis, appears to act in part by phosphorylation and inactivation of the PAF receptor, whereas methylene blue, which reduces 
the actions of nitric oxide, can reverse severe anaphylaxis that is refractory to conventional treatment. Taken together, these studies have shown that therapies targeting the PAF pathway might hold the potential for more specific and effective treatments for this potentially life-threatening condition.

\section{Introduction}

An anaphylactic reaction is an acute life-threatening event generally involving mast cell and basophil activation. The major triggers of anaphylaxis in the North American population are age dependent and generally include foods, drugs, and insect stings [1]. Most epidemiologic studies suggest that the incidence of anaphylaxis is increasing in both young and old individuals [2].

The severity of anaphylaxis can be stratified using several validated scoring systems [3-5]. These scoring systems differ in their specifics, but all reflect that severe anaphylaxis is an event with marked cardiovascular and/ or respiratory compromise. Clinical factors that appear to predispose to severe anaphylaxis include the presence of asthma and other co-morbid conditions, such as hypertension and coronary artery disease; use of medications, such as ASA, NSAIDs, and certain antihypertensive medications; and underlying mast cell disorders [6]. However, the mechanistic basis for severe and potentially fatal anaphylaxis is only now being studied, and relevant biomarkers are now being identified.

The pathophysiologic understanding of anaphylaxis is advancing. Treatments based on specific mediators of anaphylaxis will allow for targeted interventions in anaphylaxis. Several candidate mediators have recently been identified, including preformed and newly synthesized mediators, that could be potential therapeutic targets. In recent years, the role of platelet-activating factor (PAF), long known to be a key substance in murine anaphylaxis [7], has been shown to have a central role in severe and fatal human anaphylaxis $[8,9 \bullet]$.

\section{Platelet-activating factor}

\section{Background and characteristics of platelet-activating}

factor PAF is a newly synthesized phospholipid mediator secreted by many cell types and possessing pleiotropic effects [10]. PAF is able to act on the vascular endothelium and bronchial smooth muscle, as well as multiple cell types. PAF directly induces histamine release from basophils, activates mast cells, induces mast cell chemotaxis and eosinophil chemotaxis, activates IL-4 production from T cells, is a mitogen for vascular smooth muscle cells, recruits neutrophils, and aggregates platelets, among many other functions [11].

PAF acts through the PAF receptor. The PAF receptor has been demonstrated on many cells, including mast cells, eosinophils, basophils, macrophages, monocytes, endothelial cells, and others. Expression of the PAF receptor is regulated at many levels [12,13], including at the level of transcription, as well as by both phosphorylation and by intracellular cAMP levels. Residues in the carboxy-terminal cytoplasmic tail serve as a phosphorylation target. Phosphorylation of these sites may modulate binding of G-proteins to the receptors, accounting for the rapid desensitization of the PAF receptor. The PAF receptor undergoes homologous desensitization, a control mechanism that potentially limits its signaling actions. Internalization or sequestration of the receptor from the cell surface into the intracellular compartment leads to downregulation of receptor numbers on the cell surface. Phosphorylation by second messenger kinases and G-protein-coupled kinases helps to maintain receptors uncoupled from G-protein, but the role of phosphorylation in receptor sequestration is not as well defined; agonist-induced phosphorylation of the cytoplasmic tail of the PAF receptor facilitates, but is not essential for, receptor sequestration. The PAF receptor has been shown to undergo a ligand-specific, temperaturedependent internalization in transfected cells. The binding of PAF to its receptor results in the initiation of downstream signaling events, including the release of nitric oxide (NO) [14], causing vascular smooth muscle relaxation, leading to circulatory collapse and uterine, airway, and coronary smooth muscle contraction.

PAF is a highly potent vasoactive mediator. The typical serum concentration of PAF in healthy individuals is generally less than $400 \mathrm{pg} / \mathrm{ml}$, whereas it can exert its biologic effects at concentrations as low as $10^{-12} \mathrm{~mol} / \mathrm{l}$ [15]. It is inactivated by the enzyme platelet-activating factor acetylhydrolase (PAF-AH). The half-life of PAF is 
determined by the serum concentration of PAF-AH and is typically in the order of minutes [8].

\section{Data supporting a role for platelet-activating factor} in anaphylaxis in experimental animals

Data from experimental animals support the important role of PAF in anaphylaxis [16-18]. PAF can cause severe cardiac and respiratory symptoms and is involved in the biphasic allergic response. In numerous studies of animal models of anaphylaxis, PAF was elevated in the systemic circulation in proportion to the severity of anaphylaxis. The direct injection of exogenous PAF in mice causes decreased peripheral vascular tone, decreased myocardial contractility, and increased end-diastolic and pulmonary artery pressures, as well as smooth muscle contraction in the coronary arteries, gut, and uterus [19]. PAF receptor knock-out mice were resistant to experimental anaphylaxis, as compared with wild-type mice [20]. In mice without active IgE or IgG receptors, and therefore resistant to anaphylaxis, reconstitution with wild-type neutrophils restored allergen-induced anaphylaxis. This effect was shown to be due to the release of PAF from neutrophils via IgG receptors. In addition, transfer of human neutrophils was also able to restore anaphylaxis [21•].

\section{Clinical data supporting a role for the platelet- activating factor pathway in severe and fatal anaphylaxis}

There are compelling clinical data in support of a pivotal role for PAF in severe and fatal anaphylaxis in humans. Serum concentrations of PAF are significantly higher in severe anaphylaxis [8] than in milder allergic reactions and controls. The level of the enzyme that hydrolyzes PAF to a biologically inactive form, PAF$\mathrm{AH}$, correlates with the severity of anaphylaxis in pa- tients with acute anaphylaxis $[8,9 \bullet]$. In addition, the PAF-AH level is lower in fatal anaphylaxis than in controls with nonfatal anaphylaxis, controls with life-threatening and non-life-threatening asthma, and patients who die from nonallergic causes [8]. Intracutaneous PAF injection causes both an earlyand a late-phase reaction in humans [22], suggesting that PAF contributes to the biphasic response to allergen. Very recently, a low basal PAF-AH level was reported to be a risk factor for severe reactions to Hymenoptera stings [23•]. Inhaled PAF has been documented to cause bronchoconstriction [24, 25].

The current treatment for severe anaphylaxis is prompt intramuscular administration of epinephrine [26] with supportive measures, including postural maneuvers to support blood flow to the brain and administration of intravenous fluids. Additional supportive medications include antihistamines and bronchodilators. The use of epinephrine for anaphylaxis was first reported in the 1960s and is based on empiric observation and expert opinion. Epinephrine acts through multiple pathways and mechanisms, although the exact action in anaphylaxis is acknowledged to be nonspecific and unknown. In addition, epinephrine has many side effects and a narrow therapeutic window [27]. More directed treatments with a wide safety margin are needed for anaphylaxis.

Current treatment options directly related to PAF are limited. The purpose of this review is to summarize the recent advances in the understanding of the role of PAF in severe anaphylaxis, with particular attention to clinically available and preclinical therapeutic interventions related to the actions of this chemical mediator.

\section{Treatment}

- This section discusses medications with respect to their relation to the PAF pathway, with the express purpose of illustrating the role of blocking the effects of PAF in anaphylaxis. The clinically available medications-epinephrine, methylene blue, and rupatidine-are not specific to the PAF pathway, but aspects of their mechanisms of action support the role of PAF in anaphylaxis. Epinephrine has been shown to reduce the effects of PAF in vitro. The successful use of 
methylene blue, which reduces the manifestations of one of the key downstream effectors of PAF, NO, has been reported in refractory anaphylaxis. The antihistamine rupatidine has both anti-PAF and antihistamine effects.

- The preclinical agents reviewed below are targeted to the effect of PAF in severe anaphylaxis but are not available for human use at this time. Nevertheless, they provide the most compelling evidence to support the role of targeting PAF to treat or prevent severe anaphylaxis.

\section{Pharmacologic treatment}

- The aims of drug therapy are to rapidly reverse the cardiovascular and respiratory complications of anaphylaxis to reduce morbidity and mortality. In the future, medications may have the goal of preventing anaphylaxis in selected patient populations.

\section{$\beta$-adrenergic agonist}

- Epinephrine is the first-line agent for the treatment of anaphylaxis [26]. This recommendation is based on expert opinion and observation because there are no high-quality studies to support its use [28].

- Epinephrine has multiple pharmacologic actions, including $\beta$-adrenergic activity and $\beta 1$-adrenergic vasoconstrictor activity [29]. This section will concentrate on the actions of epinephrine that are relevant to the PAF pathway.

- Epinephrine has been shown to reduce PAF-induced prostaglandin release [30•]. In cultured human vascular smooth muscle cells (HVSMCs) stimulated with PAF, prostaglandin $\mathrm{E}_{2}\left(\mathrm{PGE}_{2}\right)$ was released in a time- and dose-dependent manner. Incubation of HVSMCs with epinephrine reduced PAF-mediated prostaglandin release, with the greatest effect being seen if epinephrine was added before PAF stimulation of HVSMCs. The effect on $\mathrm{PGE}_{2}$ release was reduced as the time of the addition of epinephrine after PAF stimulation was increased. The ability of epinephrine to reduce prostaglandin release in this model was prevented by $\beta$-blockade with propranolol. In this model, epinephrine acts through the $\beta$-adrenergic receptor to modify PAF-induced prostaglandin release in HVSMCs.

- The function and expression of the PAF receptor is known to be controlled by multiple factors, including intracellular cAMP levels [12]. To further elucidate how signaling through the $\beta$-adrenergic 
Standard dosage $\quad 0.01 \mathrm{mg} / \mathrm{kg}$ IM to a body weight of $30 \mathrm{~kg}$. For a body weight of $>30 \mathrm{~kg}, 0.1-$ $0.5 \mathrm{mg}$ of a 1:1000 solution IM every 5-15 minutes as needed.

Contraindications There are no absolute contraindications to use of epinephrine in the setting of acute anaphylaxis. Caution is advised in patients with heart disease, diabetes, psychiatric disease, closed angle glaucoma, or pregnancy.

Main drug interactions The efficacy of epinephrine in the treatment of anaphylaxis is reduced in persons taking $\beta$-blockers.

Main side effects A detailed discussion of epinephrine can be found in other reviews. Epinephrine has a narrow therapeutic window and can cause severe side effects, including arrhythmias, pulmonary edema, hypertension [31], and cerebral hemorrhage [32]. More commonly, epinephrine leads to side effects of pallor, tremor, and anxiety [29].

Special points Up to one third of patients will require more than one injection of epinephrine, so access to at least two doses is recommended [33]. At very low doses, epinephrine may cause vasodilatation and increased release of mediators through its action on $\beta 2$ adrenergic receptors [29].

Cost/cost effectiveness Epinephrine is inexpensive when purchased in unit dose vials. When supplied in autoinjectors, the cost is approximately $\$ 50-100$ per autoinjector.

\section{Guanylate cyclase inhibitor}

Methylene blue

- Methylene blue is indicated for the treatment of drug-induced methemoglobinemia, as well as in imaging applications such as sentinel node biopsies [34], but it is also included in anaphylaxis guidelines as an agent to consider in the treatment of anaphylaxis [35]. No formal clinical trial of methylene blue in the treatment of anaphylaxis has been undertaken.

- Methylene blue was postulated to be effective in treating anaphylaxis with hypotension in 1997 [36]. Methylene blue competes with NO to inhibit guanylate cyclase, thereby preventing synthesis of cyclic guanosine monophosphate (cGMP) and resultant smooth muscle relaxation and vasodilation.

- PAF induces NO synthesis. Direct injection of PAF had a reduced physiologic effect in mice treated with a nonselective NO synthase inhibitor as well as in endothelial NO synthase (eNOS) knock-out mice. Together, these observations show that PAF exerts its effects through NO and that the NO is generated through eNOS [37, 38]. 
Standard dosage

Contraindications

Main drug interactions

Main side effects

Special points

Cost/cost effectiveness
The effect of methylene blue is illustrated in Fig. 1.

- Clinical case reports have shown that methylene blue is effective in reversal of refractory anaphylaxis with hypotension [36]. Recently, methylene blue was used successfully in treating a patient with refractory anaphylaxis with upper airway obstruction but without hypotension [39•].

In anaphylaxis, methylene blue $1 \%$ has been administered at a dose of $1.5-$ $2 \mathrm{mg} / \mathrm{kg}$ IV in a solution of $5 \%$ dextrose [36].

Caution is advised in renal failure and G6PD deficiency. It should not be administered subcutaneously, because of the risk of necrotic abscess. It is a category $\mathrm{C}$ drug with respect to pregnancy. No safety information is available for lactation [34].

Methylene blue is a monoamine oxidase inhibitor and can produce serotonin syndrome if used with serotonergic medications [34].

Methylene blue may cause anaphylaxis, even in patients who have not been exposed to this dye before. A well-documented case of anaphylaxis occurred on first exposure for fallopian tube imaging [40]. Positive skin prick tests and in vitro leukocyte histamine release assay supported the diagnosis. However, anaphylaxis to methylene blue is very rare [41]. Methylene blue can cause fever, hypertension, chest pain, diaphoresis, headache, dizziness, confusion, nausea, vomiting, and abdominal pain [34].

Because of the blue color, methylene blue interferes with pulse oximetry and can cause blue urine and stools [34].

Methylene blue is generic and is inexpensive.

- The PAF receptor is a G-protein-coupled transmembrane receptor, which triggers multiple intracellular signaling pathways and is responsible for both immediate actions as well as new gene transcription [42]. There are two alternatively spliced transcripts of the PAF receptor, and PAF receptor expression can be modified via multiple mechanisms [12].

- The PAF receptor is able to recognize PAF, as well as oxidized PAFlike compounds [43].

- PAF receptor antagonists (PAF-RAs) block the action of PAF by competing with binding at the level of the receptor. Numerous naturally occurring compounds with PAF-RA activity have been discovered, and a number of potent PAF-RAs have been synthesized [44].

- The PAF-RAs have been studied extensively in experimental models of anaphylaxis but have not yet been studied in human anaphylaxis. Experience in experimental models suggests that these compounds show great promise in the treatment and prevention of anaphylaxis. 


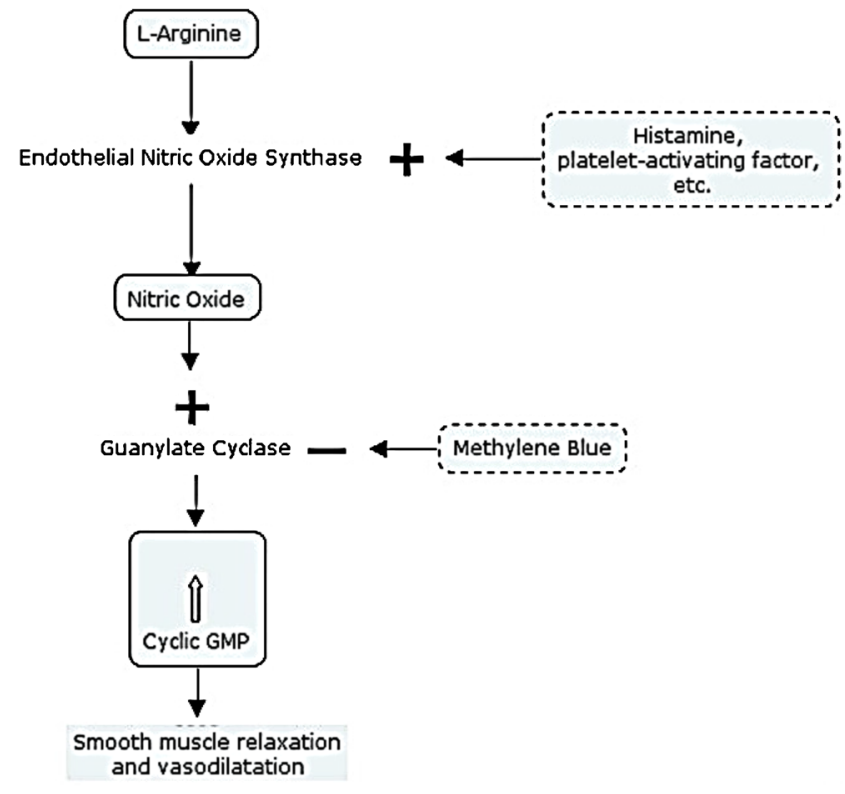

Fig. 1. Endothelial nitric oxide synthase converts L-arginine to nitric oxide, a reaction that is upregulated in the presence of histamine and platelet-activating factor. Nitric oxide increases the activation of guanylate cyclase, which then increases cyclic guanosine monophosphate (cyclic GMP). These events result in smooth muscle relaxation and vasodilation. + indicates upregulates/activates, - indicates downregulates/inhibits. Reprinted from [39•] with permission from Elsevier. http://www.sciencedirect.com/science/ journal/07356757.

Synthetic platelet-activating factor receptor antagonists

- There are multiple synthetic PAF-RA compounds. In this section, CV3988, CV6209, WEB2086, WEB2170, ABT-491, UK74505, and SR27417A will be discussed.

In experimental models

CV3988 protected mice from death due to PAF injection and due to anaphylaxis from bovine serum albumin (BSA) injection [45]. Importantly, CV3988 was effective if given prior to or after allergen challenge, suggesting that PAF-RA may have potential as a rescue treatment for anaphylaxis. WEB2086 attenuated the late cardiac manifestations of anaphylaxis in ovalbumin-sensitized guinea pigs when used in combination with the $\mathrm{H} 1$ and $\mathrm{H} 2$ receptor antagonists mepyramine and cimetidine but had little effect on its own [46]. The antihistamines alone prevented early cardiac effects but did not prevent death. In this model, blocking PAF and histamine was more effective in preventing severe anaphylaxis than blocking either mediator alone.

Additional studies have shown that the protective effect on anaphylaxis of combining a PAF-RA with an antihistamine is even more profound. In ovalbumin-sensitized BALB/c mice, CV6209 reduced anaphylactic hypotension, whereas the $\mathrm{H} 1$ antihistamine diphenhydramine worsened hypotension. In addition, a synergistic effect was seen in which the two compounds almost completely prevented hypotension [47].

In a different murine model in which mice were orally sensitized with peanut protein, antagonism of PAF with the oral PAF-RA ABT-491, given 1 hour prior to peanut challenge, reduced the symptoms of anaphylaxis [48]. Greater protection was achieved by blocking both histamine and PAF, although blocking histamine alone did not have an effect. 
In clinical studies

The synergistic effect of combined PAF and histamine receptor blockade can be partially explained by the observations that histamine can induce PAF release [49] and PAF can induce histamine release [50].

Animal studies with PAF-RAs have shown that they have variable effects on bronchoconstriction and edema, depending on different pathophysiologic states and animal models. For example, PAF-RAs, including WEB2170 and CV6209, failed to prevent PAF-induced bronchoconstriction in guinea pigs sensitized to ovalbumin but did prevent lung edema [51]. Paw edema caused by PAF injection was reduced by WEB2170 in sensitized mice far more than in sensitized mice that had received an additional (booster) injection of antigen [52].

Conversely, in anaphylaxis in mice, WEB2170 was shown to protect against death from PAF-induced and allergen-induced anaphylaxis in the mice that had received a booster injection of antigen and in those that did not [53]. Additionally, the dose of WEB2170 needed to prevent PAF-induced death was 16 times lower than the dose needed to protect against PAF-induced paw edema in unsensitized mice. These studies demonstrate that different mechanisms account for bronchoconstriction, edema, and anaphylaxis.

There have been no clinical studies of the efficacy of PAF-RA in anaphylaxis. However, they have been studied in allergic asthma. The experience with PAF-RA in asthma has been reviewed [54].

The PAF-AH UK74505 looked promising in a trial of 12 healthy males [55]. In this study, UK74505 was administered orally at 25 or $100 \mathrm{mg}$. Three and 24 hours after ingesting UK74505, subjects inhaled PAF. The lower dose of UK74505 was able to prevent bronchoconstriction from PAF inhalation 3 hours after UK74505 inhalation and the higher dose of UK74505 also prevented PAF-induced bronchoconstriction at 24 hours. In addition, UK74505 was able to reduce neutrophil changes and levels of other mediators such as LTE4. However, when studied in a randomized, double-blind, placebo-controlled crossover study in asthmatic patients, a $100 \mathrm{mg}$ dose had no effect on the early or late response, despite showing evidence of bioavailability via potent effects on platelet aggregation [56].

Similarly, WEB2086 abolished the bronchoconstriction caused by inhaled PAF in humans [57], but clinical trials of this PAF-RA in asthma were disappointing. Administered at higher doses orally 3 times daily for a week prior to challenges, it had no significant effect on either histamine- or allergen-induced bronchoconstriction [58]. In a 12-week placebo-controlled study of WEB2086 in subjects with chronic asthma on inhaled corticosteroids, there was no effect on the ability to taper inhaled corticosteroids, peak expiratory flow, time to relapse, or symptom score [59].

SR27417A is considered to be a very potent PAF-RA. At doses of $10 \mathrm{mg}$ per day taken for a week prior to allergen challenge, this compound attenuated the late but not the early allergen-induced asthmatic response [60].

From a pharmacologic standpoint, some synthetic PAF-RA compounds are very appealing as a prophylactic treatment. For example, a single $2.5 \mathrm{mg}$ oral dose of SR27417A can inhibit platelet aggregation for more than 24 hours in humans [61]. As discussed above, in animal models, intravenous PAF-RA preparations have been shown to be effective in treating anaphylaxis when given before or after antigen exposure [45]. Therefore, PAF-RA compounds have potential both as rescue medications for acute anaphylaxis and as treatments for long-term prevention. 
Special points The clinical trials of synthetic PAF-RA in allergic asthma used monotherapy, and the observed effects on bronchoconstriction were insignificant or minor. However, there was evidence of an ability to lessen the late effect of allergen exposure, which is in keeping with animal models in which PAF-RAs protected against late cardiovascular death.

It is possible that the PAF-RA compounds may be more efficacious if used synergistically with antihistamines, given that a synergistic effect with PAFRAs and antihistamines has been well demonstrated in animal models. Animal models have shown that different pathophysiologic states respond differently to PAF-RAs, and so the clinical results in asthma may not apply to anaphylaxis.

Naturally occurring platelet-activating factor receptor

antagonists

In experimental models

In clinical studies

- The naturally occurring PAF-RAs are ginkgolides, kadsurenones, and glitoxins [63]. They have been studied in experimental models and in humans. In this section, the ginkgolides BN52021 and BN52063 will be briefly discussed.

BN52021 is the best-studied PAF-RA. This compound, derived from the Ginkgo biloba tree, has been shown to antagonize bronchoconstriction due to PAF, passive sensitization, and active sensitization to antigen in guinea pigs $[64,65]$.

In a guinea pig model in which the animals were sensitized to ovalbumin, BN52021 effectively blocked bronchoconstriction with first intratracheal exposure after sensitization, but if the animals received a booster injection of allergen, BN52021 was much less effective [66]. As discussed in the previous section, a booster injection did not reduce the efficacy of the synthetic PAFRA WEB2170 [53] in preventing death from anaphylaxis in mice. Therefore, the effects of PAF-RA compounds on anaphylaxis need to be studied in the setting of anaphylaxis, as extrapolation between models may not be possible.

Oral administration of a mixture of ginkgolides (BN52063) inhibited PAF-induced wheal and flare responses in nonatopic subjects [67] and late-onset wheal and flare responses in atopic subjects [68]. In patients with asthma, ginkgolides reduced the immediate response to inhaled allergen challenge [69].

Inhaled BN52021 (also known as ginkgolide B) completely prevented PAFrelated bronchoconstriction in asthmatic children. Importantly, BN52021 also inhibited bronchoconstriction caused by inhaled allergen challenge in a subset of asthmatic children. It was able to prevent the PAF-related reduction in eosinophils and neutrophils in nonasthmatics but not in asthmatics [70]. Pharmacokinetic studies on ginkgolides have been performed. As one example, the oral absorption of ginkgolide B from a standardized Gingko biloba extract is slowed by food and the half-life of ginkgolide B ranges from about 4 hours under fasting conditions to over 10 hours after a meal [71]. Inves- 

Contraindications Ginkgo biloba is contraindicated when there is hypersensitivity to the com- pound. There is no specific contraindication for breast feeding or pregnancy, but the safety of Gingko-derived compounds has not been proven in these settings [73].
Complications In all of these clinical trials for asthma, the PAF-RAs were well tolerated. No serious side effects of ginkgolide B have been reported from trials for any of its uses [73]. Ginkgo compounds may interfere with platelet aggregation. It is often recommended to withhold ginkgolides for 3 days prior to surgical procedures. Rare cases of spontaneous bleeding have been associated with use of Ginkgo biloba.
Special points Human trials are in progress, investigating use of Ginkgo biloba extracts for several indications [http://www.clinicaltrials.gov/ct2/ results?term=gingko\&pg=2]. These compounds require further study for use in anaphylaxis.

\section{Platelet-activating factor acetylhydrolase}

- PAF-AH is the enzyme that hydrolyzes PAF, to form a biologically inactive compound, lysoPAF. It is a circulating enzyme present in picogram amounts in serum. The lower limit of normal serum activity is $20 \mathrm{nmol} / \mathrm{ml} / \mathrm{min}$ [8]. It is secreted from the liver and cells of the myeloid lineage, predominantly macrophages [74].

- There are two intracellular isoforms and one extracellular isoform of PAF-AH [12]. In human plasma, PAF-AH is bound to high- and lowdensity lipoproteins (HDL and LDL). Plasma PAF-AH activity can be influenced by altering the lipid composition and structure of the lipoproteins [74].

- The activity of PAF-AH is specific for choline phosphoglycerides with a short-chain fatty acid at the sn-2 position [12]. This enzyme is therefore able to hydrolyze PAF, as well as structurally similar compounds, including PAF-like lipids [75, 76].

- PAF-AH may exert both pro-inflammatory and anti-inflammatory actions, depending on the available substrates [77].

- In experimental models, the secretion of PAF-AH was altered by PAFRA compounds in rat hepatocytes [78]. Some PAF-RA compounds reduced the secretion of PAF-AH and also reduced its activity. However, other PAF-RA compounds increased PAF-AH secretion in these cells. This adds another layer of complexity to the therapeutic potential of modifying the PAF pathway.

Recombinant platelet-activating factor acetylhydrolase

- PAF-AH is available as an IV preparation.

- Pretreatment of mice with $1 \mathrm{mg} / \mathrm{kg}$ intravenous recombinant human PAF-AH (rPAF-AH) 15 minutes before challenge reduced mortality in 
Special points

mice caused by exogenous PAF injection from $100 \%$ to $0 \%$. In antigen-induced anaphylaxis, treatment with rPAF-AH reduced mortality from $100 \%$ to $20 \%$ [79].

- In humans, a relative deficiency of PAH-AH has been linked to death from anaphylaxis [8]. A strong inverse correlation of PAF-AH activity with the severity of anaphylaxis has been observed in patients with acute anaphylaxis $[8,9 \bullet]$. A low basal PAF-AH is a risk factor for severe reactions to Hymenoptera stings [23•].

- A recombinant human PAF-AH has been used in a phase IIa clinical trial for asthma but with disappointing results [80]. In this placebocontrolled trial, a $1 \mathrm{mg} / \mathrm{kg}$ dose of rPAF-AH was given in a single intravenous dose. The target dose in this trial was a plasma level of rPAF-AH of $10 \mathrm{mcg} / \mathrm{ml}$. A non-statistically-significant trend toward a reduction in the sputum neutrophil count was found, but the allergen-induced dual-phase asthmatic response was not significantly altered. The authors suggested that future studies of rPAF-AH in asthma should target those patients with neutrophil-predominant disease.

- Transient drowsiness has been reported at $3 \mathrm{mg} / \mathrm{kg}$ IV dosing, and 1 of 12 subjects experienced fatigue during the trial conducted by Henig et al. [80].

Considerations: PAF-AH is a protein. As such, it might be suitable for IV administration in the treatment of acute anaphylaxis, but, without an oral or subcutaneous route, it would be unlikely to be a candidate for chronic therapy. It was well tolerated in trials, but, as with other biologic agents, there would be a potential risk of developing anaphylaxis with repeated administration.

Asthma is a very complicated, heterogeneous disease, in which there are many phenotypes and variable cell populations. The results of rPAF-AH in human asthma may not apply to human anaphylaxis.

Dual histamine and platelet-activating factor receptor antagonists

- One second-generation antihistamine with both selective peripheral H1 receptor antagonist and PAF receptor antagonist activities approved for human use is rupatadine [81]. Rupatadine is not FDA approved at the time of writing but is available in the UK, Europe, South America, and India.

- There are, as yet, no data supporting use of rupatadine in anaphylaxis, although such studies would be of interest.

- The lowest available dose of epinephrine in autoinjectors is $0.15 \mathrm{mg}$, which does not provide adequate flexibility for use in children with a 
body weight of less than $15 \mathrm{~kg}$.

- Neonates are at risk of serious side effects from methylene blue [34], such as hemolytic anemia, pulmonary edema, and others.

\section{Compliance with Ethics Guidelines}

\section{Conflict of Interest}

Julia Upton declares that she has no conflict of interest.

Peter Vadas has provided expert testimony in medical legal cases of injury due to anaphylaxis and owns US patent no. 8257697 ("Use of platelet activating factor acetylhydrolase as a biomarker for anaphylaxis"); however, no money was issued to him or his institution.

\section{Human and Animal Rights and Informed Consent}

This article does not contain any studies with human or animal subjects performed by any of the authors.

\section{References and Recommended Reading}

Papers of particular interest, published recently, have been highlighted as:

- Of importance

1. Boden SR, Burks WA. Anaphylaxis: a history with emphasis on food allergy. Immunol Rev. 2011;242:247-57.

2. Sicherer SH, Sampson HA. Food allergy: epidemiology, pathogenesis, diagnosis, and treatment. J Allergy Clin Immunol. 2014;133:291-307.e5.

3. Brown SG. Clinical features and severity grading of anaphylaxis. J Allergy Clin Immunol. 2004;114:371-6.

4. Cox L, Larenas-Linnemann D, Lockey RF, et al. Speaking the same language: the World Allergy Organization Subcutaneous Immunotherapy Systemic Reaction Grading System. J Allergy Clin Immunol. 2010;125:569-74.

5. Mueller HL. Diagnosis and treatment of insect hypersensitivity. J Asthma Res. 1966;3:331-3.

6. Simons FE, Frew AJ, Ansotegui IJ, et al. Risk assessment in anaphylaxis: current and future approaches. J Allergy Clin Immunol. 2007;120:S2-24.

7. Strait RT, Morris SC, Yang M, et al. Pathways of anaphylaxis in the mouse. J Allergy Clin Immunol. 2002;109:658-68.

8. Vadas P, Gold M, Perelman B, et al. Platelet-activating factor, PAF acetylhydrolase and severe anaphylaxis. N Engl J Med. 2008;358:28-35.

9. $\quad$ Brown SG, Stone SF, Fatovich DM, et al. Anaphylaxis: clinical patterns, mediator release, and severity. J Allergy Clin Immunol. 2013;132:1141-9.
This work confirms the finding that low PAF-AH levels are associated with severe anaphylaxis

10. Zimmerman GA, McIntyre TM, Prescott SM, et al. The platelet-activating factor signaling system and its regulators in syndromes of inflammation and thrombosis. Crit Care Med. 2002;30:S294-301.

11. Kasperska-Zajac A, Brzoza Z, Rogala B. Platelet activating factor as a mediator and therapeutic approach in bronchial asthma. Inflammation. 2008;31:11220.

12. Stafforini DM, McIntyre TM, Zimmerman GA, et al. Platelet-activating factor, a pleiotrophic mediator of physiological and pathological processes. Crit Rev Clin Lab Sci. 2003;40:643-72.

13. Brown SL, Jala VR, Raghuwanshi SK, Nasser MW, et al. Activation and regulation of platelet-activating factor receptor: role of $\mathrm{G}(\mathrm{i})$ and $\mathrm{G}(\mathrm{q})$ in receptor-mediated chemotactic, cytotoxic, and cross-regulatory signals. J Immunol. 2006;177:3242-9.

14. Moritoki H, Hisayama T, Takeuchi S, et al. Involvement of nitric oxide pathway in the PAF-induced relaxation of rat thoracic aorta. Br J Pharmacol. 1992;107:196-201.

15. Venable ME, Zimmerman GA, McIntyre TM, et al. Platelet-activating factor: a phospholipid autacoid with diverse actions. J Lipid Res. 1993;34:691-702. 
16. Yost CC, Weyrich AS, Zimmerman GA. The platelet activating factor (PAF) signaling cascade in systemic inflammatory responses. Biochimie. 2010;92:692-7.

17. Bruhns P. Properties of mouse and human IgG receptors and their contribution to disease models. Blood. 2012;119:5640-9.

18. Finkelman FD. Anaphylaxis: lessons from mouse models. J Allergy Clin Immunol. 2007;120:506-15.

19. Montrucchio G, Alloatti G, Camussi G. Role of platelet-activating factor in cardiovascular pathophysiology. Physiol Rev. 2000;80:1669-99.

20. Ishii S, Kuwaki T, Nagase T, et al. Impaired anaphylactic responses with intact sensitivity to endotoxin in mice lacking a platelet-activating factor receptor. J Exp Med. 1998;187:1779-88.

21. Jönsson F, Mancardi DA, Kita Y, et al. Mouse and human neutrophils induce anaphylaxis. J Clin Invest. 2011;121:1484-96.

This important work demonstrates that IgG, IgG receptors, neutrophils, and PAF play a major role in anaphylaxis

22. Basran GS, Page CP, Paul W, et al. Platelet-activation factor: a possible mediator of the dual response to allergen? Clin Allergy. 1984;14:75-9.

23. Pravettoni V, Piantanida M, Primavesi L, et al. Basal platelet-activating factor acetylhydrolase: prognostic marker of severe Hymenoptera venom anaphylaxis. J Allergy Clin Immunol.

2014;133:1218-20.

This work suggests that PAF has a significant contribution to human anaphylaxis because lower than normal PAF-AH activity was found to be a risk factor for severe anaphylaxis

24. Cuss FM, Dixon CMS, Barnes PJ. Effects of inhaled platelet activating factor on pulmonary function and bronchial responsiveness in man. Lancet. 1986;2:189-92.

25. Smith U, Rubin AE, Patterson R. Mechanism of platelet activating factor-induced bronchoconstriction in humans. Am Rev Respir Dis. 1988;137:1015-9.

26. Simons FER, Ardusso LRF, Bilo MB, et al. World Allergy Organization guidelines for the assessment and management of anaphylaxis. J Allergy Clin Immunol. 2011;127:593e1-22.

27. Simons FER. Anaphylaxis. J Allergy Clin Immunol. 2010;125:S161-81.

28. Sheikh A, Simons FE, Barbour V, et al. Adrenaline auto-injectors for the treatment of anaphylaxis with and without cardiovascular collapse in the community. Cochrane Database Syst Rev. 2012;8, CD008935.

29. Simons KJ, Simons FER. Epinephrine and its use in anaphylaxis: current issues. Curr Opin Allergy Clin Immunol. 2010;10:354-61.

30. Vadas P, Perelman B. Effect of epinephrine on platelet-activating factor-stimulated human vascular smooth muscle cells. J Allergy Clin Immunol. 2012;129:1329-33.
This in vitro study illustrates that epinephrine can modify the effect of PAF by modifying PAF receptor expression

31. Simons FER, Sheikh A. Anaphylaxis: the acute episode and beyond. BMJ. 2013;346:f602.

32. Wendt $\mathrm{M}$, Audebert $\mathrm{H}$, Nolte $\mathrm{CH}$. Intracerebral hemorrhage following epinephrine application for anaphylactic reaction. Clin Neurol Neurosurg. 2011;113:699-700.

33. Lieberman PL. Recognition and first-line treatment of anaphylaxis. Am J Med. 2014;127:S6-11.

34. Ginimuge PR, Jyothi SD. Methylene blue: revisited. J Anaesthesiol Clin Pharmacol. 2010;26:517-20.

35. Lieberman P, Nicklas RA, Oppenheimer J, et al. The diagnosis and management of anaphylaxis practice parameter: 2010 update. J Allergy Clin Immunol. 2010;126:477-80.e1-42. Erratum in: J Allergy Clin Immunol. 2010;126:1104.

36. Evora PR, Simon MR. Role of nitric oxide production in anaphylaxis and its relevance for the treatment of anaphylactic hypotension with methylene blue. Ann Allergy Asthma Immunol. 2007;99:306-13.

37. Cauwels A, Janssen B, Buys E, et al. Anaphylactic shock depends on PI3K and eNOS-derived NO. J Clin Invest. 2006;116:2244-51.

38. Lowenstein C, Michel T. What's in a name? eNOS and anaphylactic shock. J Clin Invest. 2006;116:2075-8.

39. Bauer CS, Vadas P, Kelly KJ. Methylene blue for the treatment of refractory anaphylaxis without hypotension. Am Emerg Med. 2013;31:264e3-5.

This case report illustrates that blocking the effect of nitric oxide, known to be released by PAF, can be effective in anaphylaxis that is refractory to conventional therapy, even in the absence of hypotension

40. Dewachter P, Mouton-Faivre C, Tréchot P, et al. Severe anaphylactic shock with methylene blue instillation. Anesth Analg. 2005;101:149-50.

41. Mertes PM, Alla F, Tréchot $P$, et al. Anaphylaxis during anesthesia in France: an 8-year national survey. J Allergy Clin Immunol. 2011;128:366-73.

42. Honda Z, Ishii S, Shimizu T. Platelet-activating factor (PAF) receptor. J Biochem (Tokyo). 2002;131:771-9.

43. Heery JM, Kozak M, Stafforini DM, et al. Oxidatively modified LDL contains phospholipids with platelet-activating factor-like activity and stimulates the growth of smooth muscle cells. J Clin Invest. 1995;96:2322-30.

44. Koltai M, Hosford D, Guinot P, et al. Platelet activating factor: a review of its effects, antagonists, and possible future clinical implications (part 1). Drugs. 1991;42:9-29.

45. Terashita Z, Imura Y, Shino A, et al. A lethal role of platelet activating factor in anaphylactic shock in mice. J Pharmacol Exp Ther. 1987;243:378-83.

46. Felix SB, Baumann G, Hashemi T, et al. Characterization of cardiovascular events mediated by platelet 
activating factor during systemic anaphylaxis. J Cardiovasc Pharmacol. 1990;15:987-97.

47. Shibamoto T, Liu W, Cui S, et al. PAF, rather than histamine, participates in mouse anaphylactic hypotension. Pharmacology. 2008;82:114-20.

48. Arias $\mathrm{K}$, Baig $\mathrm{M}$, Colangelo $\mathrm{M}$, et al. Concurrent blockade of platelet-activating factor and histamine prevents life-threatening peanut-induced anaphylactic reactions. J Allergy Clin Immunol. 2009;124:30714 .

49. Kajiwara N, Sasaki T, Bradding P, et al. Activation of human mast cells through the platelet-activating factor receptor. J Allergy Clin Immunol. 2010;125:1137-45.

50. McIntyre TM, Zimmerman GA, Satoh K, et al. Cultured endothelial cells synthesize both platelet-activating factor and prostacyclin in response to histamine, bradykinin, and adenosine triphosphate. J Clin Invest. 1985;76:271-80.

51. Pretolani M, Lefort J, Vargaftig BB. Limited interference of specific PAF antagonist with hyyperresponsiveness to PAF itself of lungs from actively sensitized guinea-pigs. Br J Pharmacol. 1989;97:433-42.

52. Amorim CZ, Martins MA, Cordeiro RSB, et al. Differential inhibition by the PAF receptor antagonist, WEB 2170, of allergic inflammation in single sensitized and boosted mice. Eur J Pharmacol. 1992;211:29-34.

53. Amorim CZ, Cordeiro RS, Vargaftig BB. Involvement of platelet-activating factor in death following anaphylactic shock in boosted and in unboosted mice. Eur J Pharmacol. 1993;235:17-22.

54. Kasperska-Zajac A, Brzoza Z, Rogala B. Platelet-activating factor (PAF): a review of its role in asthma and clinical efficacy of PAF antagonists in the disease therapy. Recent Patents Inflamm Allergy Drug Discov. 2008;2:72-6.

55. O'Connor BJ, Uden S, Carty TJ, et al. Inhibitory effect of UK,74505, a potent and specific oral platelet activating factor (PAF) receptor antagonist, on airway and systemic responses to inhaled PAF in humans. Am J Respir Crit Care Med. 1994;150:35-40.

56. Kuitert LM, Angus RM, Barnes NC, et al. Effect of a novel potent platelet-activating factor antagonist, modipafant, in clinical asthma. Am J Respir Crit Care Med. 1995;151:1331-5.

57. Adamus WS, Heuer HO, Meade CJ, et al. Inhibitory effects of the new PAF acether antagonist WEB-2086 on pharmacologic changes induced by PAF inhalation in human beings. Clin Pharmacol Ther. 1990;47:456-62.

58. Freitag A, Watson RM, Matsos G, et al. Effect of a platelet activating factor antagonist, WEB 2086, on allergen induced asthmatic responses. Thorax. 1993;48:594-8.
59. Spence DP, Johnston SL, Calverley PM, et al. The effect of the orally active platelet-activating factor antagonist WEB 2086 in the treatment of asthma. Am J Respir Crit Care Med. 1994;149:1142-8.

60. Evans DJ, Barnes PJ, Cluzel M, et al. Effects of a potent platelet-activating factor antagonist, SR27417A, on allergen-induced asthmatic responses. Am J Respir Crit Care Med. 1997;156:11-6.

61. Gómez FP, Roca J, Barberà JA, et al. Effect of a platelet-activating factor (PAF) antagonist, SR 27417A, on PAF-induced gas exchange abnormalities in mild asthma. Eur Respir J. 1998;11:835-9.

62. Adamus WS, Heuer H, Meade CJ, et al. Safety, tolerability, and pharmacologic activity of multiple doses of the new platelet activating factor antagonist WEB 2086 in human subjects. Clin Pharmacol Ther. 1989;45:270-6.

63. Singh P, Singh IN, Mondal SC, et al. Platelet-activating factor (PAF)-antagonists of natural origin. Fitoterapia. 2013;84:180-201.

64. Braquet P, Etienne A, Touvay C, et al. Involvement of platelet activating factor in respiratory anaphylaxis, demonstrated by PAF-acether inhibitor BN 52021. Lancet. 1985;1(8444):1501.

65. Vilain B, Lagente V, Touvay $\mathrm{C}$, et al. Pharmacological control of the in vivo passive anaphylactic shock by the PAF-acether antagonist compound BN 52021. Pharmacol Res Commun. 1986;18(Suppl):119-26.

66. Desquand $S$, Lefort J, Dumarey $C$, et al. Interference of BN 52021, an antagonist of PAF, with different forms of active anaphylaxis in the guinea-pig: importance of the booster injection. Br J Pharmacol. 1991;102:687-95.

67. Chung KF, Dent G, McCusker M, et al. Effect of a ginkgolide mixture (BN 52063) in antagonising skin and platelet responses to platelet activating factor in man. Lancet. 1987;1(8527):248-51.

68. Roberts NM, Page CP, Chung KF, et al. Effect of a PAF antagonist, BN52063, on antigen-induced, acute, and late-onset cutaneous responses in atopic subjects. J Allergy Clin Immunol. 1988;82:236-41.

69. Guinot P, Brambilla C, Duchier J, et al. Effect of BN 52063, a specific PAF-acether antagonist, on bronchial provocation test to allergens in asthmatic patients. A preliminary study. Prostaglandins. 1987;34:723-31.

70. Hsieh KH. Effects of PAF antagonist, BN52021, on the PAF-, methacholine-, and allergen-induced bronchoconstriction in asthmatic children. Chest. 1991;99:877-82.

71. Fourtillan JB, Brisson AM, Girault J, et al. Pharmacokinetic properties of bilobalide and ginkgolides $\mathrm{A}$ and B in healthy subjects after intravenous and oral administration of Ginkgo biloba extract (EGb 761). Therapie. 1995;50:137-44

[Article in French] 
72. Woelkart K, Feizlmayr E, Dittrich P, et al. Pharmacokinetics of bilobalide, ginkgolide $\mathrm{A}$ and $\mathrm{B}$ after administration of three different Ginkgo biloba L. preparations in humans. Phytother Res. 2010;24:445-50.

73. McKenna DJ, Jones K, Hughes K. Efficacy, safety, and use of Ginkgo biloba in clinical and preclinical applications. Altern Ther Health Med. 2001;7:70-86, 88-90.

74. Karasawa K. Clinical aspects of plasma platelet-activating factor-acetylhydrolase. Biochim Biophys Acta. 2006;1761:1359-72.

75. Stremler KE, Stafforini DM, Prescott SM, et al. An oxidized derivative of phosphatidylcholine is a substrate for the platelet-activating factor acetylhydrolase from human plasma. J Biol Chem. $1989 ; 264: 5331-4$

76. Stremler KE, Stafforini DM, Prescott SM, et al. Human plasma platelet-activating factor acetylhydrolase. Oxidatively fragmented phospholipids as substrates. J Biol Chem. 1991;266:11095103.
77. Karabina SA, Ninio E. Plasma PAF-acetylhydrolase: an unfulfilled promise? Biochim Biophys Acta. 2006;1761:1351-8.

78. Svetlov SI, Howard KM, Miwa M, et al. Interaction of platelet-activating factor with rat hepatocytes: uptake, translocation, metabolism, and effects on PAFacetylhydrolase secretion and protein tyrosine phosphorylation. Arch Biochem Biophys. 1996;327:11322.

79. Fukuda Y, Kawashima H, Saito K, et al. Effect of human plasma-type platelet-activating factor acetylhydrolase in two anaphylactic shock models. Eur J Pharmacol. 2000;390:203-7.

80. Henig NR, Aitken ML, Liu MC, et al. Effect of recombinant human platelet-activating factoracetylhydrolase on allergen-induced asthmatic responses. Am J Respir Crit Care Med. 2000;162:523-7.

81. Merlos M, Giral M, Balsa D, et al. Rupatadine, a new potent, orally active dual antagonist of histamine and platelet-activating factor (PAF). J Pharmacol Exp Ther. 1997;280:114-21. 